\title{
Aspectos Socioambientais da Comercialização de Pequi em Goiás
}

\author{
Cleiton Silva Oliveira ${ }^{1}$, Lucas Emanuel Nunes Gonçalves ${ }^{1}$, \\ Marcos Pelegrini Coutinho ${ }^{1}$, Ney Peixoto ${ }^{1}$, Alcides Gatto ${ }^{2}$ \\ ${ }^{1}$ Departamento de Engenharia Florestal, Universidade Estadual de Goiás - UEG, Ipameri/GO, Brasil \\ ${ }^{2}$ Departamento de Engenharia Florestal, Universidade de Brasília - UnB, Brasília/DF, Brasil
}

\begin{abstract}
RESUMO
O pequizeiro fornece frutos tradicionalmente utilizados na culinária goiana e regiões do bioma Cerrado. Partindo da análise da comercialização de pequi na Central de Abastecimento de Goiás S/A (Ceasa - GO) e em feiras locais (Ipameri e Pires do Rio - GO), o presente estudo avalia a importância da espécie e ameaças relacionadas ao extrativismo. Os dados revelaram 12 microrregiões produtoras de pequi no estado, sendo comercializados 5,5 mil toneladas de pequi em 2011, com o preço da caixa variando de 25 a 40 reais. Nas feiras, o preço pago por litro em 2010 foi de cinco reais, com um percentual crescente de interessados na venda desse produto não madeireiro. Chama atenção a variação no preço pago ao pequi e mudanças nas regiões produtoras em Goiás, além da aquisição desse produto de outros estados. Para suprir a demanda crescente de pequi, sugere-se, além do extrativismo responsável, o plantio da espécie no Cerrado, em pomares ou sistemas agroflorestais.
\end{abstract}

Palavras-chave: extrativismo vegetal, comercialização, indicadores sociais.

\section{Social and Environmental Aspects of Pequi Marketing in Goiás}

\begin{abstract}
The pequizeiro provides fruits traditionally used in cooking Goiás and regions of the Cerrado biome. Based on the pequi marketing analysis in CEASA-GO and local fairs (Ipameri and Pires do Rio, GO), this study assesses the importance of the species and threats related to extraction. The data revealed 12 micro-regions producing pequi in the state, being sold 5500 tons of pequi in 2011, with the box price ranging from 25 to 40 reais. The price paid in the fairs per liter in 2010 was five Brazilian Reais, with an increasing percentage of interested in the sale of non-timber product. The variation in the price paid to the pequi and changes producing regions in Goiás is noteworthy, in addition to the purchase of this product from other states. To meet the growing demand of pequi, it is suggested, besides the responsible extraction, planting the species in the cerrado, in orchards or agroforestry systems.
\end{abstract}

Keywords: extraction plant, marketing, social indicators.

\section{INTRODUÇÃO}

O bioma Cerrado apresenta grande diversidade de espécies vegetais produtoras de frutos que podem ser consumidas in natura na alimentação humana e/ou animal. O pequizeiro (Caryocar brasiliense Camb.) é uma espécie típica do bioma que apresenta valor econômico pela utilização de seus frutos na culinária 
e na fabricação de licores e xaropes medicinais, como também pela árvore inteira (Damiani, 2006).

Apesar da importância do pequi para a alimentação de várias famílias que habitam a região do Cerrado, bem como para a indústria de cosméticos e farmacêutica, essa planta, assim como outros recursos naturais (flora e fauna) que são de interesse socioeconômico para as populações dessa região, está sendo gradativamente reduzida para dar lugar ao estabelecimento de extensas áreas de produção agropecuária, sem estudo mais intensivo do emprego de suas potencialidades (Oliveira et al., 2005). Para o cerrado, a produção não madeireira tem se mostrado uma importante estratégia de desenvolvimento econômico e de estímulo à conservação do bioma (Afonso, 2012).

Ressalta-se que os produtos não madeireiros são cada vez mais evidenciados, não só pelo seu uso nas comunidades, mas também por seu valor comercial (Afonso et al., 2015; Boxall et al., 2003), revelando-se como atividade capaz de gerar renda, induzir o desenvolvimento local e a conservação dos ecossistemas.

Sob os pontos de vista econômico, ecológico e social, as informações sobre a produção e a comercialização dos produtos provenientes do pequizeiro são dispersas e parciais, principalmente quanto aos seus potenciais agrícola e industrial (Aquino et al., 2008; Rocha et al., 2008).

Nesse sentido, buscou-se levantar dados sobre a comercialização de pequi na Ceasa-GO e sobre o extrativismo de espécie nos municípios de Ipameri e Pires do Rio, de forma a conhecer a importância dessa planta nos mercados locais e regionais.

\section{MATERIAL E MÉTODOS}

\subsection{Comercialização de pequi na central de abastecimento}

Inicialmente, esse estudo levantou informações sobre a comercialização de pequi na Ceasa-GO referente aos anos de 2007 a 2011, a partir das análises conjunturais disponibilizadas no site do referido órgão. As variáveis consideradas foram quantidade de pequi comercializado (toneladas/ano) e preço pago (reais) ao produto, analisando-se os números de Goiás, com foco nas principais microrregiões e municípios produtores (safras de 2010 e 2011), provenientes de outros estados, e a quantidade comercializada.

\subsection{Entrevistas nas feiras}

A segunda etapa foi realizada nos municípios de Ipameri e Pires do Rio, em 2010, região sudeste de Goiás (Figura 1), durante o período de comercialização de pequi. Nessa etapa, por meio de entrevistas, a partir de questionário pré-elaborado, levantaram-se informações da espécie, como forma de coleta dos frutos (árvore ou solo) e onde se coletam (Cerrado ou pastagens) e dos feirantes (nível de escolaridade, tempo na atividade, valor do produto, entre outras). Nessa etapa, dois acadêmicos de Engenharia Florestal da Universidade Estadual de Goiás identificaram os pontos de comercialização de pequi e, em seguida, houve explicação da pesquisa ao vendedor e preenchimento dos questionários. $\mathrm{Na}$ ocasião, foram entrevistados dez feirantes em Pires do Rio e cinco em Ipameri, com os resultados apresentados a seguir.

\section{RESULTADOS E DISCUSSÃO}

As informações sobre a comercialização de pequi no estado de Goiás ainda carecem de sistematização, mas destacam-se as análises conjunturais sob a coordenação da Ceasa-GO que, a partir de 2007, disponibilizou informações de produtos oriundos do pequi (frutos e conserva) comercializados no estado.

O total comercializado de frutos nos últimos anos variou de 3.570,24 toneladas (t), em 2008, a 5.549,82 t, em 2011 (Tabela 1). O valor pago ao extrativista pela caixa de $32 \mathrm{~kg}$ de frutos variou de 25 a 40 reais, movimentando mais de 4 milhões de reais somente em 2011.

Nota-se que a comercialização de pequi na Ceasa-GO é decorrente de frutos coletados em Goiás, com percentuais de 70,0 44,5 26,1, 68,3 e 39,7\%, respectivamente, para 2007 a 2011, bem como de outros estados (30,0 55,5, 73,9, 31,7 e 60,3\%). Esses valores percentuais mostram que quando a produção em Goiás é relativamente baixa, a demanda pelo produto é suprida por fontes de outros estados. Também se observa, na Tabela 1, que tem aumentado a demanda por pequi, considerando o montante comercializado de Goiás e oriundo de outros estados. 


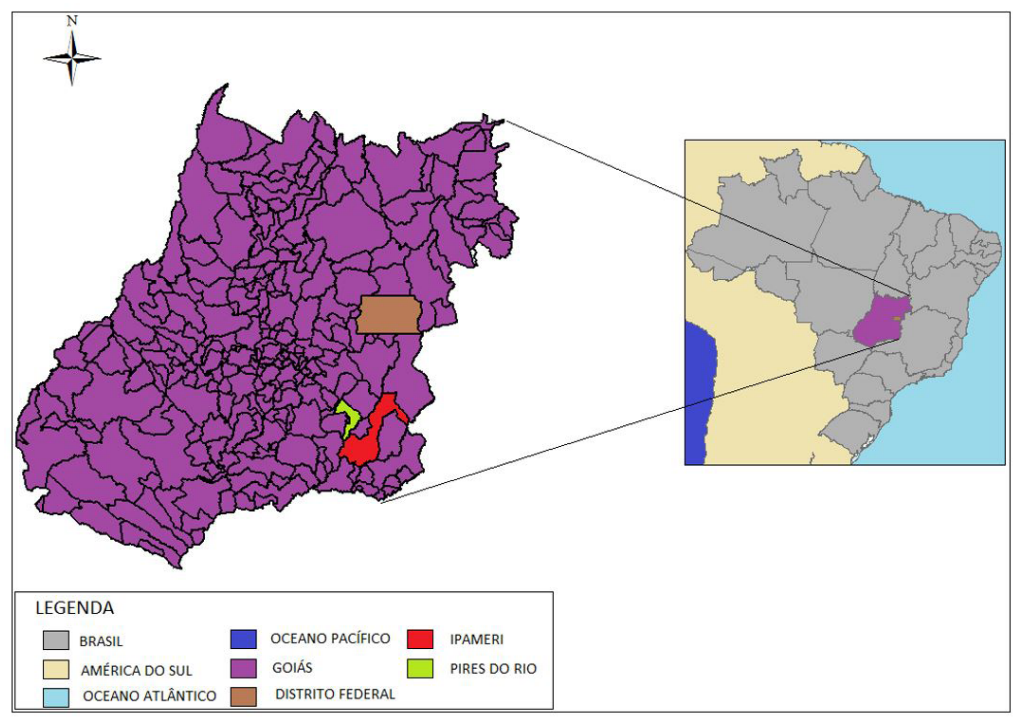

Figura 1. Destaca os municípios de Ipameri e Pires do Rio, estado de Goiás, onde as entrevistas foram realizadas. Figure 1. It highlights the municipalities of Ipameri and Pires do Rio, state of Goiás, where the interviews were conducted.

Tabela 1. Comercialização de pequi na Ceasa-GO proveniente do estado de Goiás e de outros estados, no período de 2007 a 2011.

Table 1. Marketing pequi in the CEASA-GO from the state of Goiás and other states in the period 2007-2011.

\begin{tabular}{|c|c|c|c|c|c|}
\hline \multirow{2}{*}{ Ano } & \multicolumn{2}{|c|}{ Goiás } & \multicolumn{2}{|c|}{ Outros estados } & \multirow{2}{*}{$\begin{array}{c}\text { Total } \\
\text { Toneladas }\end{array}$} \\
\hline & Toneladas & $\%$ & Toneladas & $\%$ & \\
\hline 2007 & $2.872,95$ & 70,0 & $1.231,27$ & 30,0 & $4.104,22$ \\
\hline 2008 & $1.588,13$ & 44,5 & $1.982,11$ & 55,5 & $3.570,24$ \\
\hline 2009 & $1.010,78$ & 26,1 & $2.864,67$ & 73,9 & $3.875,46$ \\
\hline 2010 & $3.595,14$ & 68,3 & $1.668,67$ & 31,7 & $5.263,81$ \\
\hline 2011 & $2.207,26$ & 39,7 & $3.342,56$ & 60,3 & $5.549,82$ \\
\hline
\end{tabular}

Fonte: elaborada pelos autores.

O fato de haver abastecimento com pequi de outros estados pode estar relacionado à sazonalidade de produção de frutos das árvores em Goiás, onde os picos de produção foram observados para 2007 e 2010, com a comercialização de 2.872,95 e 3.595, 14 toneladas, respectivamente, do estado.

As microrregiões e municípios fornecedores de pequi no estado de Goiás, conforme análise conjuntural da Ceasa-GO, em 2011 e 2010, são Nova Crixás, Pilar, Porangatu, Chapada dos Veadeiros, Ceres, Anápolis, Goiânia, Meia Ponte, Vale do Rio dos Bois, Vão do Paranã, Anicuns e Pires do Rio (Tabela 2).

Notou-se em relação a 2010 que os municípios de Nova Crixá, Ceres, Anápolis e Pires do Rio, bem como a microrregião Chapada dos Veadeiros, aumentaram sua participação na produção de pequi na Ceasa-GO ou foram inseridos como novas microrregiões em 2011 (Pires do Rio). Já as microrregiões de Pilar, Porangatu, Goiânia, Vale do Rio dos Bois, Vão do Paranã, Anicuns e Meia Ponte diminuíram sua participação ou tiveram suas microrregiões não computadas no mesmo ano.

Também pode explicar a saída de alguns municípios e o surgimento de outros a própria sazonalidade na produção de frutos no estado ou, ainda, que estes estão chegando à Ceasa-GO via outras microrregiões produtoras. Além disso, pode ser que o pequi onde a coleta e a venda são atividades tradicionais supra apenas os mercados locais, ou seja, feiras municipais e cidades vizinhas, deixando de ser enviado à Ceasa. Rocha et al. (2008), analisando a dinâmica do extrativismo de pequi, 
Tabela 2. Microrregiões e municípios produtores de pequi em 2011 e 2010 no estado de Goiás.

Table 2. Microregions and municipalities pequi producers in the years 2011 and 2010 and their respective shares of the fruit in the state of Goiás.

\begin{tabular}{|c|c|c|c|c|}
\hline Ano & \multicolumn{2}{|c|}{2011} & \multicolumn{2}{|c|}{2010} \\
\hline Microrregião/municípios & Toneladas & $(\%)$ & Toneladas & $(\%)$ \\
\hline Nova Crixás & 395,20 & 17,91 & 281,85 & 7,84 \\
\hline Pilar & 347,52 & 15,74 & $1.416,45$ & 39,40 \\
\hline Aragarças & 383,36 & 17,37 & 487,52 & 13,56 \\
\hline Porangatu & 346,56 & 15,70 & $1.077,44$ & 29,97 \\
\hline Chapada dos Veadeiros & 142,40 & 6,45 & 2,08 & 0,06 \\
\hline Ceres & 98,56 & 4,47 & 0,64 & 0,02 \\
\hline Anápolis & 238,88 & 10,82 & 20,26 & 0,56 \\
\hline Anicuns & - & - & 92,80 & 2,58 \\
\hline Goiânia & 133,15 & 6,03 & 156,42 & 4,35 \\
\hline Vão do Paranã & - & - & 17,60 & 0,49 \\
\hline Vale do Rio dos Bois & - & - & 18,08 & 0,50 \\
\hline Meia Ponte & 11,23 & 0,51 & 24,00 & 0,67 \\
\hline Pires do Rio & 110,40 & 5,00 & - & - \\
\hline Total & $2.207,26$ & 100,00 & $3.595,14$ & 100,00 \\
\hline
\end{tabular}

Fonte: CEASA (2010, 2011), adaptada pelos autores.

observaram oscilações de produção tanto no arranjo geográfico quanto em relação às safras regionais ao longo do tempo.

Embora significativos, os números são subestimados, uma vez que somente parte do que é comercializado utiliza este canal para escoar o produto, conforme observou Oliveira et al. (2005). Esses autores avaliaram o arranjo produtivo do pequi em Iporá (GO) e evidenciaram que as atividades extrativista e de comercialização do pequi, na região estudada, apresentaram dimensão econômica comparável à das principais atividades agrícolas da agricultura familiar, destacando-se como atividade de inclusão social por absorver mão de obra pouco qualificada e remunerar acima da média, em relação às atividades agrícolas.

Na região norte de Minas, a renda média (valor bruto) de uma família que trabalha com o pequi, principalmente com a comercialização do óleo, é cerca de $\mathrm{R} \$ 450,00$ por safra, o que pode corresponder a $5,5 \%$ da renda anual familiar (Oliveira \& Scariot, 2010). Agroextrativistas que comercializam a própria produção conseguem vender o litro de óleo em feiras livres por aproximadamente $\mathrm{R} \$ 7,00$.

Tendo 2007 como o ano-base (100\%), verifica-se o encolhimento da produção nos dois anos seguintes (2008 e 2009), conforme mostra a Tabela 1, produzindo 86,98 e $94,42 \%$ em relação ao ano-base. Tais dados podem estar relacionados com o grande volume de sementes produzidas em um ano, ocasionando exaustão dos indivíduos produtores nas safras seguintes. Já em 2010 e 2011, verificou-se um incremento significativo na oferta das sementes de pequi, crescendo 28,25 e 35,22\% em relação ao ano-base. Tais valores demonstram cada vez mais a importância do produto para o extrativismo local, agregando renda aos agricultores rurais.

Afonso \& Angelo (2009) constataram que a produção dos principais produtos florestais dos não madeireiros de ocorrência no Cerrado diminuiu durante o período de 1982 a 2005, com exceção do pequi e da copaíba, que apresentaram tendências crescentes na produção e taxas anuais de crescimento positivas (8,5\% e $12,9 \%$, respectivamente).

\subsection{Resultados das entrevistas}

De acordo com as entrevistas, em Ipameri e Pires do Rio, o pequi é coletado e vendido pelo próprio coletor ou familiar nos meses de outubro a dezembro. O preço varia dentro da época de colheita e entre os anos, em função de a produção, oferta e demanda anual ser variável. Segundo Oliveira et al. (2005), o preço pago pelos comerciantes na aquisição do pequi em casca ou descascado sofre variações durante a safra, aumentando conforme a escassez do produto, sendo os meses de maior comercialização de outubro a dezembro, corroborando com os resultados ora obtidos. 
Para Pereira et al. (2002), a utilização dessa riqueza abundante do Cerrado está restrita aos meses de safra, quando ocorre intensa comercialização dos frutos; mesmo assim, estima-se que $50 \%$ da produção seja perdida após a colheita, por deficiências na classificação, no transporte e no armazenamento.

A forma de coleta de pequi no chão corresponde a $70 \%$ do total de frutos coletados, sendo o restante coletado diretamente na árvore (30\%). Ressalta-se, ainda, o fato de ser a forma mais indicada, pois não causa danos à árvore e os frutos estão maduros e com maior quantidade de vitaminas e proteínas (Oliveira \& Scariot, 2010).

Em geral, os frutos são coletados em áreas de pastagem (70\%), em Cerrado nativo (20\%) e em Cerrado e pasto (10\%). Segundo Pereira (2002), a maior parte das populações da espécie já sofreu degradação ou foi completamente eliminada e a maioria das populações remanescentes vem tendo sua regeneração afetada pela coleta indiscriminada de frutos para comercialização.

A obtenção de informações sobre a comercialização de pequi nas microrregiões produtoras torna-se estratégica para a definição de planos e ações locais de orientação quanto ao manejo sustentável e fornecimento de produtos de qualidade (fruto, polpa, conservas, óleo e licor). Pode ser um passo importante para o fortalecimento dessa importante cadeia extrativista, conforme menciona Oliveira et al. (2005), que carece de política para estimular o seu desenvolvimento, pois conforme constatado na pesquisa (Figura 2), a cada ano novas pessoas são atraídas para a atividade.

As pessoas que realizam a coleta do pequi são atraídas pela oportunidade de obter uma renda extra durante o período de colheita, sobretudo as pessoas sem emprego formal, no meio rural. Cabe destacar que, a cada safra, quando se tem um bom preço do produto, novos catadores entram nessa atividade, pois para $40 \%$ dos entrevistados 2010 foi o primeiro ano de coleta e venda de pequi.

Embora as pessoas entrevistadas declarem ser alfabetizadas (70\%), observou-se que o extrativismo do pequi é praticado por pessoas com baixo grau de escolaridade ou até mesmo sem escolaridade, pois a maioria possui somente o primeiro grau completo. Essa constatação foi também evidenciada em pesquisa de Oliveira et al. (2005), que estudou o arranjo produtivo de pequi na cidade de Iporá (GO), onde a escolaridade dos trabalhadores variou desde $3^{\circ}$ série do $1^{\circ}$ grau até o $1^{\circ}$ ano do nível superior; destes, $9 \%$ terminaram o $2^{\circ}$ grau, $82 \%$ não terminaram a segunda fase do $1^{\circ}$ grau e $9 \%$ não terminaram a primeira fase do $1^{\circ}$ grau.

Os entrevistados mencionaram que nas áreas de coleta é comum a presença dos seguintes animais: arara, cobra, veado e tatu. Além disso, em algumas fazendas, a coleta não é permitida. Tal fato pode significar, nos locais com Cerrado e corredores de vegetação nativa, a exemplo das matas de galeria e ciliares da região, que a fauna continuará se alimentando das flores, frutos e caroços (Oliveira et al., 2011), sendo uma atividade menos agressiva à biodiversidade local na medida em que contribui para valorizar e conservar espécies nativas.

Os pequizeiros oferecem às comunidades do campo e das cidades diferentes formas de trabalho, ao entrarem na agenda governamental. A exemplo do Programa de Garantia de Preços Mínimos voltado à sociobiodiversidade, o extrativismo poderá melhorar a qualidade de vida das pessoas, incrementado a renda e promovendo sustentabilidade nas regiões de ocorrência da espécie. No âmbito nacional, o Programa de Aquisição de Alimentos (PAA), instituído pela Lei $\mathrm{n}^{\circ} 10.696$, de 2 de julho de 2003, regulamentado pelo Decreto $\mathrm{n}^{\circ} 4.772$, de 2 de julho de 2003, vem apoiando o beneficiamento e a comercialização de produtos florestais não madeireiros (Afonso, 2012).

Para Silva (2011), o extrativismo praticado por comunidades rurais insere-se como uma alternativa econômica ao desmatamento, à monocultura e à degradação social.

Todavia, a oferta de produtos de pequi depende complementarmente, cada vez mais, de plantios (enriquecimento ou pomares), além de assistência técnica, apoio à cadeia produtiva e pesquisa para

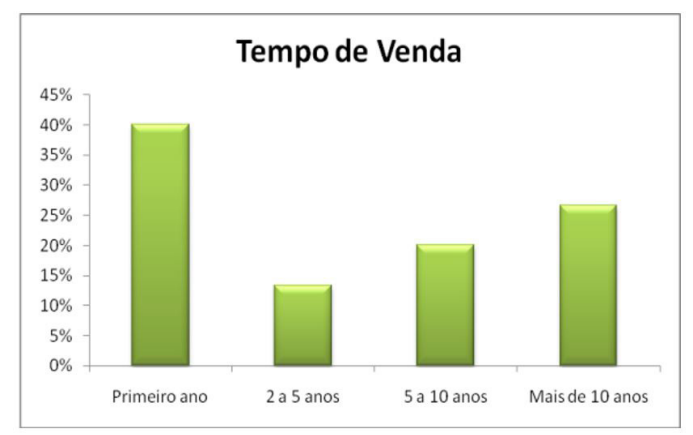

Figura 2. Tempo de permanência na atividade extrativista e venda de pequi.

Figure 2. Residence time in the extraction activity and selling Pequi. 
garantir a sobrevivência da espécie e das populações que dela necessitam. Conforme observa Silva (2011), a expansão do extrativismo e consumo origina também um problema de desequilíbrio ecológico, principalmente relacionado ao ciclo de reprodução do pequizeiro e dos ecossistemas circunvizinhos à planta e à área de coleta.

\section{CONCLUSÕES}

- As microrregiões de Pilar, Porangatu e Nova Crixa destacam-se como as principais áreas fornecedoras de pequi na Ceasa-GO e nos anos de menor safra, este é suprido por outros estados;

- A comercialização de pequi, em feiras de cidades do interior, embora não faça parte das estatísticas oficiais, fornece renda alternativa, alcançando alguns feirantes até duzentos reais por final de semana, em 2010, quando o preço pago por litro de pequi em Pires do Rio e Ipameri foi de cinco reais;

- A procura por pequi, por envolver, a cada ano, um número maior de pessoas interessadas, requer políticas públicas para fortalecimento da cadeia produtiva e para o desenvolvimento de pesquisas que atendam à demanda crescente por produtos do Cerrado;

- A forma de coleta de pequi no chão, em áreas remanescentes de Cerrado ou em pastagens, é importante para a conservação da espécie e fauna e para a manutenção da qualidade do produto comercializado.

\section{STATUS DA SUBMISSÃO}

Recebido: 8 set., 2013

Aceito: 12 set., 2015

\section{AUTOR(ES) PARA CORRESPONDÊNCIA}

\section{Cleiton Silva Oliveira}

Departamento de Engenharia Florestal, Universidade Estadual de Goiás - UEG, Rodovia GO-330, Km 241, Anel Viário, CEP 75780-000, Ipameri, GO, Brasil

e-mail: cleitoncso@live.com

\section{REFERENCIAS}

Afonso SR, Angelo H, Almeida A. N. Caracterização da produção de pequi em Japonvar, MG. Floresta 2015; 45(1): 49-56. http://dx.doi.org/10.5380/rf.v45i1.33987.
Afonso SR, Angelo H. Mercado dos produtos florestais nãomadeireiros do cerrado brasileiro. Ciência Florestal 2009; 19(3): 317-328. http://dx.doi.org/10.5902/19805098887.

Afonso SR. A política pública de incentivo à estruturação da cadeia produtiva do pequi (Caryocar brasiliense) [tese]. Brasília: Universidade de Brasília; 2012.

Aquino G, Ribeiro JF, Gulias APSM, Oliveira MC, Barros CJS, Hayes KM et al. Uso sustentável das plantas nativas do Cerrado: oportunidades e desafios. In: Parron LM. Cerrado: desafios e oportunidades para o desenvolvimento sustentável. Planaltina: Embrapa Cerrados; 2008. p. 95-123.

Boxall PC, Murray G, Unterschultz JR, Boxall PC. Nontimber forest products from the Canadian boreal forest: an exploration of aboriginal opportunities. Journal of Forest Economics 2003; 9(2): 75-96. http://dx.doi. org/10.1078/1104-6899-00027.

Centrais de Abastecimento de Goiás S/A - CEASA. Análise Conjuntural 2010. Goiânia: CEASA; 2010. 353 p. n. 35.

Centrais de Abastecimento de Goiás S/A - CEASA. Análise Conjuntural 2011. Goiânia: CEASA; 2011. 335 p. n. 36.

Damiani C. Qualidade e perfil volátil de pequi (Caryocar brasiliense Camb.) minimamente processado, armazenado sob diferentes temperaturas [dissertação]. Lavras: Universidade Federal de Lavras; 2006.

Oliveira CS, Gonçalves LEN, Ferreira BS, Santos KM, Coutinho MP. Extrativismo e comercialização de pequi em Ipameri e Pires do Rio-GO. In: Anais IX Seminário de Iniciação Científica, VI Jornada de Pesquisa e Pós-Graduação e Semana Nacional de Ciência e Tecnologia; 2011; Anápolis. Anápolis: Universidade Estadual de Goiás; 2011. p. 1-3.

Oliveira E, Longhi EH, Vanderlei JC, Silva IDC, Rocha EV. Arranjo Extrativista do pequi (Caryocar brasiliense Camb.) na região de Iporá - Goiás: sustentabilidade e dinâmica da comercialização. In: Anais do $46^{\circ}$ Congresso da Sociedade Brasileira de Economia, Administração e Sociologia Rural [online]; 2005; Ribeirão Preto. Ribeirão Preto: SOBER; 2005. [citado em 2016 jan. 5]. Disponível em: http://www.sober.org.br/palestra/2/898.pdf

Oliveira WL, Scariot A. Boas práticas de manejo para o extrativismo sustentável do pequi. Brasília: Embrapa Recursos Genéticos e Biotecnologia; 2010. 84 p.

Pereira BAS. Árvores do Brasil Central: espécies da região geoeconômica de Brasília. Rio de Janeiro: IBGE; 2002.

Pereira VP, Pereira EBC, Fialho JF, Junqueira NTV, Gomes AC. Avaliação de métodos de enxertia em mudas de pequizeiro. Planaltina: Embrapa Cerrados, 2002. 14 p. Boletim de pesquisa e desenvolvimento n. 51.

Rocha MG, Rocha TC, Aguiar JLP, Junqueira NTV. Dinâmica da produção extrativista de pequi no Brasil. In: IX Simpósio Nacional do Cerrado e II Simpósio Internacional de Savanas Tropicais [CD-ROM]; 2008; Brasília. Brasília: Embrapa Cerrados; 2008.

Silva MD. Cadeia produtiva de pequi no Estado de Goiás: análise do ambiente organizacional e institucional [monografia]. Planaltina: Universidade de Brasília; 2011. 